\title{
Interdisciplinarity in Uncertain Times: Research Centers
}

\author{
Karen Burg, Vice President for Research, Kansas State University
}

$\mathrm{T}$ The Interdisciplinarity Advantage

Evolving research problems are complex, we therefore need experts and tools from multiple fields. Surprisingly, we take for granted that carpenters, plumbers, electricians, and others work together to build houses (would you make an offer on a house that was built solely by a team of plumbers?), but our existing research structure remains highly compartmentalized and we seem insecure and somewhat inept in promoting interdisciplinarity. The simple fact remains - interdisciplinary approaches allow disruptive leaps forward, rather than incremental steps. They allow more complete solutions to the world's complex problems. Interdisciplinary centers, if built thoughtfully, provide a means to realizing complete solutions. narity

The Challenges of Interdiscipli-

The barriers to interdisciplinarity in a university setting are many. The typical university is configured in units and units naturally promote territorialism. Each unit has unit specific goals, and the unit leaders and members are generally quite familiar with the goals and the rewards system. Therefore, those activities not captured within goals or rewards are generally given significantly lower to no attention. Additionally, infrastructure is built to support the unit goals. Each unit, for example, has service infrastructure (e.g. human resources, sponsored programs, etc.), so creating initiatives that span units leads to logistical issues of knowing which service units to access and how those units will handle additional workload. The perceived incentives for faculty members to participate in interdisciplinary research is low. Tenure and promotion is discipline specific, while economic development and intellectual property is not uniformly valued across a university. Interdisciplinary units are inherently more difficult to manage, for a variety of reasons, and a high university investment is required. Importantly, the return on investment is ill-defined and, although potentially extremely high, very difficult to quantitate.

Interdisciplinary is a great buzzword, but is an exceedingly difficult activity to manage. The National Academies (2014) has released many position papers promoting and outlining the concept and has provided compelling rationale for striving to achieve interdisciplinarity. Indeed, according to Popper (1963) "we are not students of some subject matter, but students of problems. And problems may cut right across the borders of any subject matter or discipline". A series of discipline related buzzwords has emerged over the years. Multi-disciplinary, for example, is a con- 
vergence of people and ideas for a defined amount of time, with generally no long-term impact. That is, upon removal of the impetus for the multi-disciplinarity, the participants return to their disciplines. Interdisciplinarity, however, is the convergence of multiple disciplines that results in longer term effects. That is, each participating discipline is richer for the experience and gains in some tangible manner. In this instance, there are marked effects on the participating disciplines. Transdisciplinary is a melded discipline; the participating disciplines contribute to the creation of a new, standalone discipline.

\section{Considerations in Purposefully}

\section{Building Interdisciplinarity}

The needs of an interdisciplinary center that is not located in a college or department are unique. Points to consider include the physical and budgetary location, the budget and deliverables, the academic review process in place, the staffing necessary from the unit or from the university, the focus on student participation (as students are centric to the university mission), and the realities of faculty involvement. A center generally spans university units and provides a collaboratory and infrastructure for teambased work. The ideal center relies on a core of permanent research faculty, rather than building on the talents of tenured or tenure track faculty, who generally have multiple responsibilities beyond the bounds of the center. Research faculty are $100 \%$ dedicated to research, yet they can connect with tenure/tenuretrack faculty who are dedicated to teaching, research, service. Research faculty provide an environment which is industry friendly - particularly with respect to goals, deliverables, and metrics - they also provide a student friendly environment - i.e. training of students in a real world, collaborative environment.

There are several classic structural problems, specific to centers. First, simple use of the term interdisciplinary does not guarantee interdisciplinarity. Seeding money for cross-disciplinary interactions in the foreground does not ensure interdisciplinarity in the long-term; typically, once the money disappears so do the participants. Often, research groups are not cohesive and do not tackle well-defined problems. Research administrators often define a list of people and disciplines, with little regard to the research problem or to the potential for integration of these individual efforts. The accounting for indirect returns, proposals submitted, etc. cannot stimulate competition with departments or the center will not survive. Often there is lack of administrative support units such as human resources or sponsored programs. There is a myth of self-sufficiency; nationally, very few institutes or centers realize complete selfsufficiency. This is typically due to an unrealistic view of return on investment and lack of a business plan. Often the center lacks a unified and unifying problem definitions and project directions.

The center is, in effect, a flexible clearinghouse. The institute or center must be independent from but complementary to departments and should serve as a hiring draw for departments (due to the ready-made collaborators and infrastructure). A permanent director is responsible for marketing and direction. 
Longer-term stability is provided by the appointment of permanent research faculty members as the core. In contrast, tenured and tenure-track faculty are involved as dictated by the scientific needs of projects and investigator availability. It has been shown that a flexible and dynamic participation model of this type provides benefits. According to Rhoten, "Researchers who felt free to enter and exit collaborative relationships reported more progress with their interdisciplinary projects and greater satisfaction in their professional lives overall".

\section{Budget and Deliverables}

Many centers and institutes are developed on the enthusiasm of the technical experts and without in-depth attention to the financials. Hence, a business plan must be developed with contributions from finance and technical personnel. A focused mission statement should provide the "filter" for investment in future projects. A realistic return on investment should be identified, along with a self-sufficiency plan and related metrics. Annual and multi-year reviews should be defined, along with assessment plans and goal setting exercises. The unit will need mavens, connectors, and salespersons (M. Gladwell, 2000). That is, needed are individuals with great expertise in the discipline but high critical thinking skills, individuals with ability to connect, and individuals with ability to communicate the value of the center. Generally center connectors include industry and education liaisons, while mavens include human resources and sponsored programs personnel. Highly functional centers incorporate research personnel with respect to technical diversity.

\section{Rewards System Overhaul}

There are several important reward concerns. In particular, effort toward and participation in a center must be recognized by tenure/promotion committees. Rewards are based on output; common output includes congressional testimonies, public policy initiatives, popular media, or product development. Center research tends to lend to multiple author publications, which incorporate different perspectives from different disciplines. Letters of support from collaborators, defining the critical role of a center researcher, can be vital to the tenure and promotion process.

\section{Center Impact}

Center education and training impact may be monitored by a count of new "languages", number of disciplines, performance in courses and retention, as well as student participation in research programs. Research metrics may be monitored by a count of publications, presentations, and intellectual property development. The metrics should be meaningful - for example, the number of disclosures filed may suggest positive impact; however, licensing is probably a more meaningful measure of translation and impact. It may be possible to identify short-term, high return intellectual property opportunities to support the broader center mission.

Thus, the described interdisciplinary center model is industry friendly, major government initiative friendly, and student friendly. Center research faculty complement departmental unit foci and provide stability. When based on existing collaboratives a center provides a rich training environment. Most importantly, 
the center provides a microenvironment

where the disciplines gain independently and collectively.

\section{References:}

Facilitating Interdisciplinary Research, National Academies, National Academies Press, 2014

Gladwell, M., Tipping Point, Little Brown (New York), 2000.

Popper, K. R. Conjectures and Refutations: The Growth of Scientific Knowledge. New York: Routledge and Kegan Paul, 1963, p. 88.

Rhoten, "D. Interdisciplinary research: Trend or transition." Items and Issues 5.1-2 (2004): 6-11. 2004 